\title{
Passive protection against Burkholderia pseudomallei infection in mice by monoclonal antibodies against capsular polysaccharide, lipopolysaccharide or proteins
}

\author{
S. M. JONES*, J. F. ELLIS, P. RUSSELL, K. F. GRIFFIN and P. C. F. OYSTON
}

Microbiology, Dstl, CBS Porton Down, Salisbury, Wiltshire SP4 OJQ, UK and*National Laboratory for Zoonotic Diseases and Special Pathogens, Canadian Science Centre for Human and Animal Health, Winnipeg, Manitoba R3E 3R2, Canada

\begin{abstract}
Burkholderia pseudomallei, the aetiological agent of melioidosis, is endemic in south-east Asia and northern Australia, where it is an important cause of human disease. There is no vaccine available and antibiotic therapy is associated with high relapse rates. A panel of seven monoclonal antibodies (MAbs) that recognise capsular polysaccharide, lipopolysaccharide or proteins was produced and their ability to protect mice passively against experimental melioidosis was evaluated. The MAbs were capable of protecting mice against intra-peritoneal challenge with $10^{4} \mathrm{cfu} / 250$ MLD of a virulent strain of $B$. pseudomallei (NCTC 4845), when pooled, and four of the MAbs were individually protective. However, at a higher $B$. pseudomallei challenge level of $10^{6} \mathrm{cfu}$ none of the MAbs afforded protection and only the anti-exopolysaccharide MAbs produced a significantly delayed time to death.
\end{abstract}

\section{Introduction}

Burkholderia pseudomallei, the causative agent of melioidosis, is widely distributed throughout the tropical countries of the world, where it exists as a free-living bacterium in soil and water [1]. The disease is an important cause of human morbidity and mortality in endemic regions; however, the true number of cases is probably much higher than reported because of difficulties in diagnosis [2]. In Australia, melioidosis causes a smaller number of human infections than in countries such as Thailand, but among livestock the disease has important economic and public health implications [3]. Melioidosis can present in many clinical forms, from acute pneumonia or septicaemia to chronic and subclinical forms of the disease. Therapy is complicated by antibiotic resistance in clinical isolates, resulting in frequent relapse of patients [4].

Received 15 May 2002; revised version received 5 July 2002; accepted 2 Aug. 2002.

Corresponding author: Dr P. C. F. Oyston (e-mail PCOYSTON@dstl.gov.uk).
No vaccine licensed for human use currently exists for protection against infection by $B$. pseudomallei. However, a protein and polysaccharide preparation has been used successfully to vaccinate captive marine mammals. This vaccine induced high levels of specific antibodies and resulted in significantly reduced mortality [5]. Avirulent strains of B. pseudomallei have also been used to vaccinate animals before respiratory challenge, but with variable results $[6,7]$.

The lipopolysaccharide (LPS) and flagellin of $B$. pseudomallei have been identified as potential candidates for use as protective immunogens $[8,9]$. $B$. pseudomallei has been shown to produce two forms of LPS, termed LPS I and LPS II [10]. Immunoglobulin G ( $\mathrm{IgG})$ responses in melioidosis patients to LPS I and II and flagellin have been studied and only the level of antibodies to LPS II was higher in patients surviving infection, indicating their potential immunological importance [11].

It has been suggested that the polysaccharide capsule of $B$. pseudomallei plays a role in environmental protection [12], immune system evasion [13,14] and attachment to epithelial cells [15]. Capsular polysac- 
charide may also allow the bacteria to resist the bactericidal effects of the phagolysosome, enabling the organism to survive within the host $[16,17]$. The evidence for this is two-fold. Firstly, a non-capsulate strain of $B$. pseudomallei produced by insertional mutagenesis was markedly less virulent than the parent strain, indicating that the capsule is critical for the virulence of $B$. pseudomallei [18]. Furthermore, another non-capsulate mutant was subsequently shown to be unable to induce a protective immune response in mice, indicating that capsular polysaccharide may be a major protective antigen [19].

After septicaemic melioidosis, serum from survivors contained IgG3 antibodies to LPS O-II polysaccharide [11]. The serum mediated killing of B. pseudomallei by polymorphonuclear leucocytes and this effect was enhanced by complement. These results suggest that antibodies specific for LPS O-polysaccharides from $B$. pseudomallei could be protective and this protection might be mediated by enhancement of phagocytosis leading to bacterial clearance.

The present study aimed to achieve passive protection with a range of monoclonal antibodies (MAbs) raised against heat-killed B. pseudomallei. The MAbs were specific for LPS, capsular polysaccharide and two proteins.

\section{Materials and methods}

\section{Bacterial strain and cultural conditions}

B. pseudomallei NCTC 4845 was grown in either nutrient broth or Luria-Bertani medium at $37^{\circ} \mathrm{C}$ with shaking for $18 \mathrm{~h}$. For viable counts, media were solidified with bacto-agar $15 \mathrm{~g} / \mathrm{L}$. The median dose inducing morbidity or mortality (MLD) for this strain is $40 \mathrm{cfu}$ in the $\mathrm{BALB} / \mathrm{c}$ mouse model (unpublished observations).

\section{Experimental animals}

Female BALB/c mice (6-8 weeks old) raised under specific-pathogen-free conditions (Charles River Laboratories, Margate) were used in this study. All animal experimentation adhered strictly to the 1986 Scientific Procedures Act and to the Guidance on the Operation of the Animals (Scientific Procedures) Act (Home Office, UK), as adopted by the ethics committee on animal experimentation within this research establishment.

\section{Preparation of LPS extracts}

LPS extracts were prepared according to the method of Chart [20]. B. pseudomallei NCTC 4845 was heatinactivated at $80^{\circ} \mathrm{C}$ for $2 \mathrm{~h}$ in $5 \mathrm{mM}$ phosphate-buffered saline (PBS) pH 7.3. The bacterial cells were harvested by centrifugation and resuspended in SDS-solubilisation buffer $(62.5 \mathrm{mM}$ Tris-HCl, $\mathrm{pH} 6.8$, containing glycerol $10 \% \mathrm{v} / \mathrm{v}, 2$-mercaptoethanol $5 \% \mathrm{v} / \mathrm{v}$, SDS $3 \% \mathrm{w} / \mathrm{v}$ and bromophenol blue $0.01 \% \mathrm{w} / \mathrm{v}$ ) at a concentration of $1 \mathrm{mg}$ (wet-weight) bacteria/30 $\mu \mathrm{l}$ of SDS-solubilisation buffer. After mixing, the tubes were incubated at $100^{\circ} \mathrm{C}$ for $10 \mathrm{~min}$. A $30-\mu \mathrm{l}$ volume of clear, boiled bacterial suspension was added to $30 \mu \mathrm{l}$ of proteinase $\mathrm{K}(3.3 \mathrm{mg}$ in $1 \mathrm{ml}$ of SDS-solubilisation buffer) and the tubes were incubated in a water bath at $60^{\circ} \mathrm{C}$ for a minimum of $1 \mathrm{~h}$. Crude LPS for immunisations was prepared by extensively dialysing the extract followed by lyophilisation.

\section{Immunisation schedule for the production of MAbs}

Female BALB/c mice (6 weeks old) were immunised by intraperitoneal injection once every 2 weeks over an 8-week period with heat-inactivated $B$. pseudomallei NCTC 4845. Each dose was equivalent to $2 \times$ $10^{8}$ cells, determined from viable counts before heat inactivation of the bacterial suspension. A further group of mice was immunised with $50 \mu \mathrm{g}$ of LPS by the same schedule. The first four injections were given with incomplete Freund's adjuvant. For the final injection, antigen was suspended in PBS and injected intravenously.

\section{Production of MAbs}

Three days after the final immunisation the mice were splenectomised and the spleen cells were fused with X63 Ag8.653 myeloma cells as described previously [21]. The culture supernatant fluids of growing clones were screened by ELISA with B. pseudomallei NCTC 4845 whole cells as antigen (see below). The resulting hybridomas were cloned by limiting dilution.

\section{ELISA methods}

ELISA for the detection of MAbs against B. pseudomalle $i$ was performed in flat-bottomed Immulon II 96well plates (Dynex Technologies, Virginia, USA). The plates were coated with heat-inactivated B. pseudomallei NCTC 4845 cells $\left(1 \times 10^{7} \mathrm{cfu} / \mathrm{ml}\right)$ in $0.05 \mathrm{M}$ carbonate-bicarbonate buffer, $\mathrm{pH} 9.6$, overnight at $4^{\circ} \mathrm{C}$. The plates were incubated with PBS-M (PBS containing milk powder $1 \% \mathrm{w} / \mathrm{v}$ ) for $1-2 \mathrm{~h}$ and then washed with PBST (PBS containing Tween-20 0.05\% $\mathrm{v} / \mathrm{v})$. Hybridoma culture supernatant fluids $(100 \mu \mathrm{l})$ and culture medium as a negative control were added and the plates were incubated for $1 \mathrm{~h}$. They were then washed with PBST before the addition of horseradish peroxidase-labelled goat anti-mouse immunoglobulin (Harlan SeraLab, Loughborough, UK) diluted 1in 5000 in PBS-M, and the plates were incubated for $1 \mathrm{~h}$. The plates were washed with PBST before adding $100 \mu \mathrm{l}$ of substrate solution - $10 \mathrm{mg}$ of $2,2^{\prime}$-azino-bis (3ethylbenzthiazoline-6-sulphonic acid) in $50 \mathrm{ml}$ of buffer $\left(28 \mathrm{ml}\right.$ of $0.1 \mathrm{M} \mathrm{Na}_{2} \mathrm{HPO}_{4}$ and $22 \mathrm{ml}$ of $50 \mathrm{mM}$ citric acid, $\mathrm{pH} 4.3$ ) with the addition of $10 \mu \mathrm{l}$ of $\mathrm{H}_{2} \mathrm{O}_{2}$ 
just before use $\left(\mathrm{OD}_{414}\right)$. The plates were incubated for $15 \mathrm{~min}$ at room temperature and the optical density at $414 \mathrm{~nm}\left(\mathrm{OD}_{414}\right)$ was measured in a Titertek Multiskan plate reader (ICN Biomedicals, Thame).

\section{Gel electrophoresis and Western blotting}

SDS-PAGE was performed according to the method of Laemmli [22] with a $12.5 \%$ separating gel $(\mathrm{pH} 8.45)$ and a $4.5 \%$ stacking gel ( $\mathrm{pH} 8.45)$; both gels contained SDS $0.1 \% \mathrm{w} / \mathrm{v}$. Samples were diluted 1 in 2 with sample buffer (SDS 4\%, 2-mercaptoethanol 10\%, 125 $\mathrm{mM}$ Tris-HCl, $\mathrm{pH} 6.8$, glycerol $10 \%$ and bromophenol blue $0.004 \%$ ), boiled at $100^{\circ} \mathrm{C}$ for $5 \mathrm{~min}$ and separated at $100 \mathrm{~V}$ for $90 \mathrm{~min}$ with Tris-glycine running buffer (50 mM Tris, $380 \mathrm{~mm}$ glycine, $\mathrm{pH} 8.3$, containing SDS $0.2 \% \mathrm{w} / \mathrm{v}$ ). Polysaccharides were silver stained with the BioRad Silver stain kit and LPS was silver stained according to the method of Chart [23]. Western blotting was performed with Immobilon-P transfer membranes (Millipore, Watford) and a semi-dry blotting system (Biometra, Göttingen, Germany). After transfer, membranes were incubated in bovine serum albumin (BSA) $5 \%$ in PBS overnight. MAbs were purified by affinity chromatography on protein G-sepharose (Pharmacia, Uppsala, Sweden) and diluted to $1 \mu \mathrm{g} / \mathrm{ml}$ in PBS containing BSA $0.1 \%$ plus normal goat serum $1 \%$. Peroxidase-conjugated goat anti-mouse immunoglobulin (Harlan SeraLab) diluted 1 in 2000 in BSAPBS $0.1 \%$ was used for final development. The substrate was 4-chloro-1-naphthol (Sigma).

\section{Passive immunisations}

In the first passive immunisation experiment, groups of 10 mice were inoculated intravenously with a cocktail of seven MAbs (Table 1). A total of $40 \mu \mathrm{g}$ of antibody was given to each animal. Of this $40-\mu \mathrm{g}$ dose, $15 \mu \mathrm{g}$ was composed of the three MAbs to exopolysaccharide, $10 \mu \mathrm{g}$ of the MAb to LPS and $15 \mu \mathrm{g}$ of the three MAbs to the proteins. The mice were then challenged intraperitoneally with either $10^{6}$ or $10^{4} \mathrm{cfu}$ of $B$. pseudomallei 4845.

In the second study, groups of five mice were inoculated intravenously with the cocktail of seven MAbs described above, $40 \mu \mathrm{g}$ of a cocktail of the three anti-exopolysaccharide MAbs, $40 \mu \mathrm{g}$ of the anti-LPS

Table 1. MAbs used in this study

\begin{tabular}{lll}
\hline $\mathrm{MAb}$ & Isotype & Target antigen \\
\hline 4VIIIAII & IgG2a $\kappa$ & Exopolysaccharide \\
3VIE5 & IgG2b $\lambda$ & Exopolysaccharide \\
4VA5 & IgG1 $\kappa$ & Exopolysaccharide \\
CC6 & IgG2a $\kappa$ & LPS \\
LF7 & IgG3 $\lambda$ & Protein \\
BA2 & IgG2a $\kappa$ & Protein \\
4VH7 & IgG2a $\kappa$ & Protein \\
\hline
\end{tabular}

MAb or $40 \mu \mathrm{g}$ of a cocktail of the three anti-protein MAbs.

In the third experiment, groups of six mice were inoculated intravenously with one of the seven MAbs. As before, the antibodies were diluted in sterile PBS to a final dose of $40 \mu \mathrm{g} /$ mouse. The mice were then challenged with $10^{4}$ or $10^{6} \mathrm{cfu}$ of $B$. pseudomallei 4845. In each experiment the antibodies were administered between 3 and $5 \mathrm{~h}$ before challenge and the controls were left untreated. Once challenged, the mice were observed twice daily for either 3 or 5 weeks and mortalities were recorded. At the end of the experiment survivors were killed and observations at post mortem examination were recorded. For all passive immunisation experiments, the significance of the differences in mean times to death was determined by Student's $t$ test in Microsoft Excel.

\section{Results}

A panel of MAbs was produced from animals immunised with heat-inactivated B. pseudomallei and, of these, seven were selected for further characterisation (Table 1). Western blotting showed that three of the antibodies recognised a high mol. wt polysaccharide (Fig. 1). Treatment of B. pseudomallei cells with sodium periodate inhibited the binding of antibody [19] illustrating that carbohydrate residues are vital for the binding of antibody. Immunofluorescent studies also showed antibody binding in a halo around $B$. pseudomallei cells [19]. These results together support the conclusion that these MAbs bound to the capsular

1

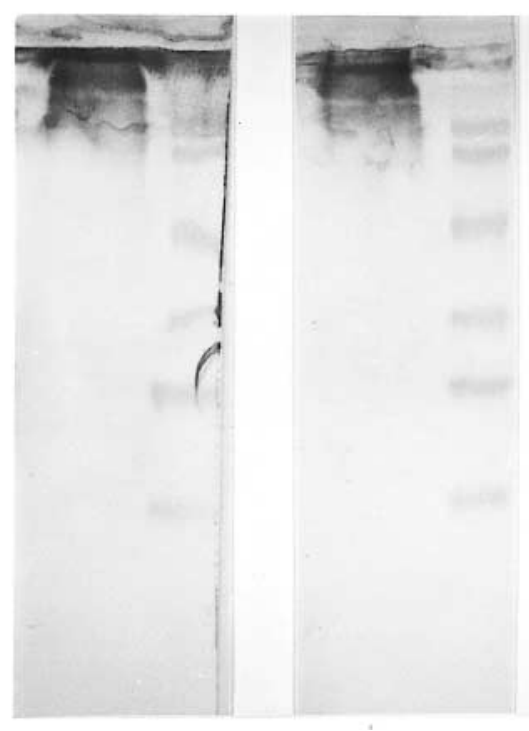

Fig. 1. Western blot of B. pseudomallei NCTC 4845 cells with the three anti-EPS MAbs: lane 1, 4IIIA11; 2, 3VIE5; 3, 4VA5. All three antibodies recognised high mol. wt polysaccharide material. Pre-stained mol. wt markers were run next to each lane; the highest marker was $120 \mathrm{kDa}$. 
polysaccharide around B. pseudomallei [24]. Three further MAbs were identified as binding to protein antigens in Western blots (not shown). The function and cellular location of these proteins was not determined. The final MAb was shown to recognise LPS in Western blots (Fig. 2).

The first passive protection study lasted for 3 weeks (Fig. 3) and all mice received a cocktail (40 $\mu \mathrm{g})$ of the seven MAbs. At the highest challenge dose of $10^{6} \mathrm{cfu}$ of B. pseudomallei 4845, all the untreated control animals died within the first 5 days. In the equivalent passively immunised group, the last animal succumbed to infection on day 10. Comparing all of the animals in these high challenge groups showed that there was a significant increase in the mean time to death $(p<0.01)$ in the passively immunised group. In the

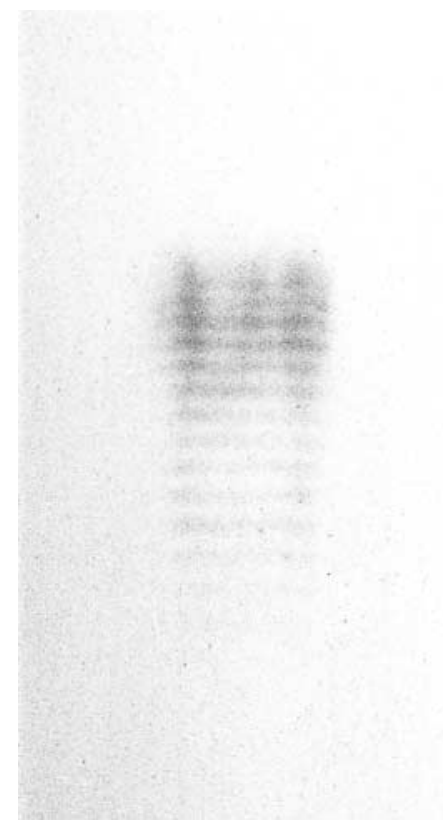

Fig. 2. Western blot showing the binding of MAb CC6 to LPS from B. pseudomallei 4845 .
$10^{4}$ cfu challenge group, all passively immunised mice survived the entire 3 -week observation period. This contrasted with seven deaths in the equivalent control group. Statistical analysis of the mean time to death of these groups demonstrated a highly significant increase in survival $(p<0.005)$. Some of the control animals appeared to develop a more chronic form of infection, which resulted in some survival in the unimmunised control groups, although post mortem revealed that the mice had internal abscesses.

In the second challenge, the duration of the experiment was increased to 5 weeks to ensure that all the untreated controls, including those that initially entered a chronic infection state, would succumb to the infection before the end of the study (Fig. 4). In addition to a group receiving the cocktail of antibodies, three groups were treated with the anti-LPS MAb, a cocktail of protein-specific MAbs or a cocktail of exopolysaccharide-specific MAbs. All groups received $40 \mu \mathrm{g}$ of antibody per mouse and were challenged with $10^{4}$ or $10^{6} \mathrm{cfu}$ B. pseudomallei 4845 . At the $10^{4} \mathrm{cfu}$ challenge dose (Fig. 4a), all the antibody preparations significantly increased the time to death compared with the untreated controls $(p<0.005)$. At the higher challenge dose (Fig. 4b) only the complete antibody cocktail and the exopolysaccharide-specific antibody cocktail gave any significant delay in the time to death compared with the untreated controls (both $\mathrm{p}<0.05$ ). At this challenge level, all the control animals died by day 3, whereas in the group given the complete cocktail there were survivors until day 18 after challenge, and in the group given anti-exopolysaccharide antibodies two mice survived the 34-day experiment. Mice in both the complete antibody cocktail and anti-exopolysaccharide groups were also significantly more protected than mice in either the anti-LPS or antiprotein groups against the $10^{6} \mathrm{cfu}$ challenge. In both the latter treatment groups, all animals died by day 3 at this challenge level.

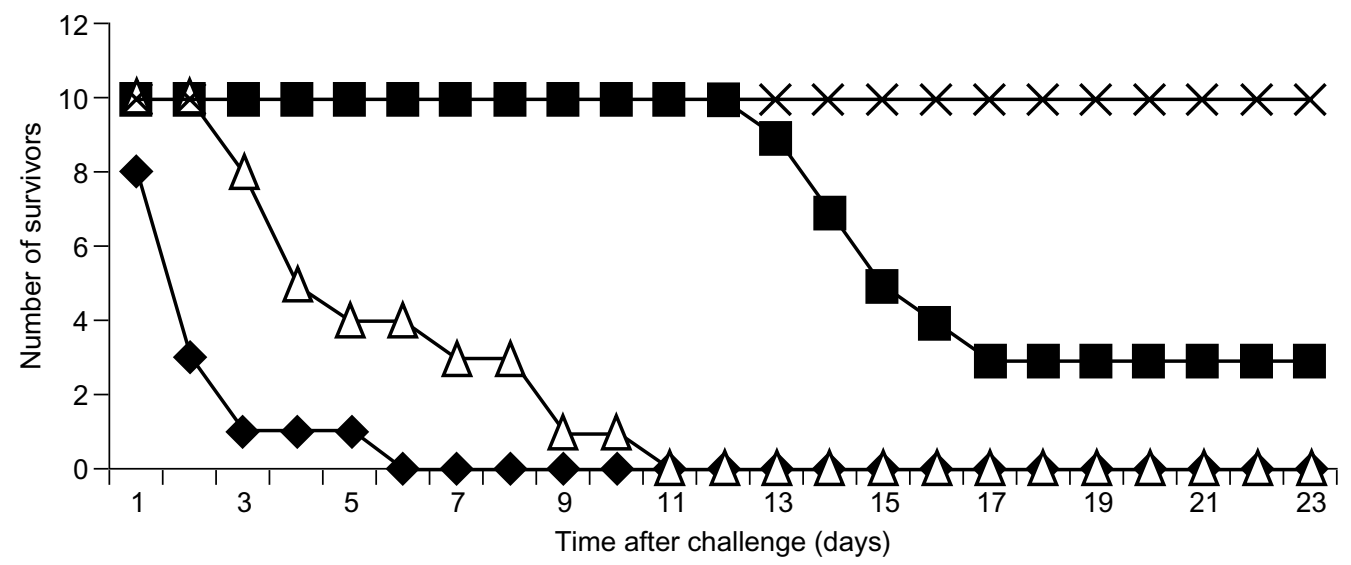

Fig. 3. Survival in passively immunised and untreated control mice following intra-peritoneal challenge with $B$. pseudomallei 4845. Passively immunised mice were given a cocktail of MAbs recognising exopolysaccharide, LPS and two proteins and challenged with $10^{4} \mathrm{cfu}(\times)$ or $10^{6} \mathrm{cfu}(\triangle)$; or naïve (control) mice were challenged with $10^{4} \mathrm{cfu}(\boldsymbol{\square})$ or $10^{6} \mathrm{cfu}(\diamond)$. $(\mathrm{n}=10$, except $\mathrm{n}=8$ control mice challenged with $10^{6} \mathrm{cfu}$ ). 


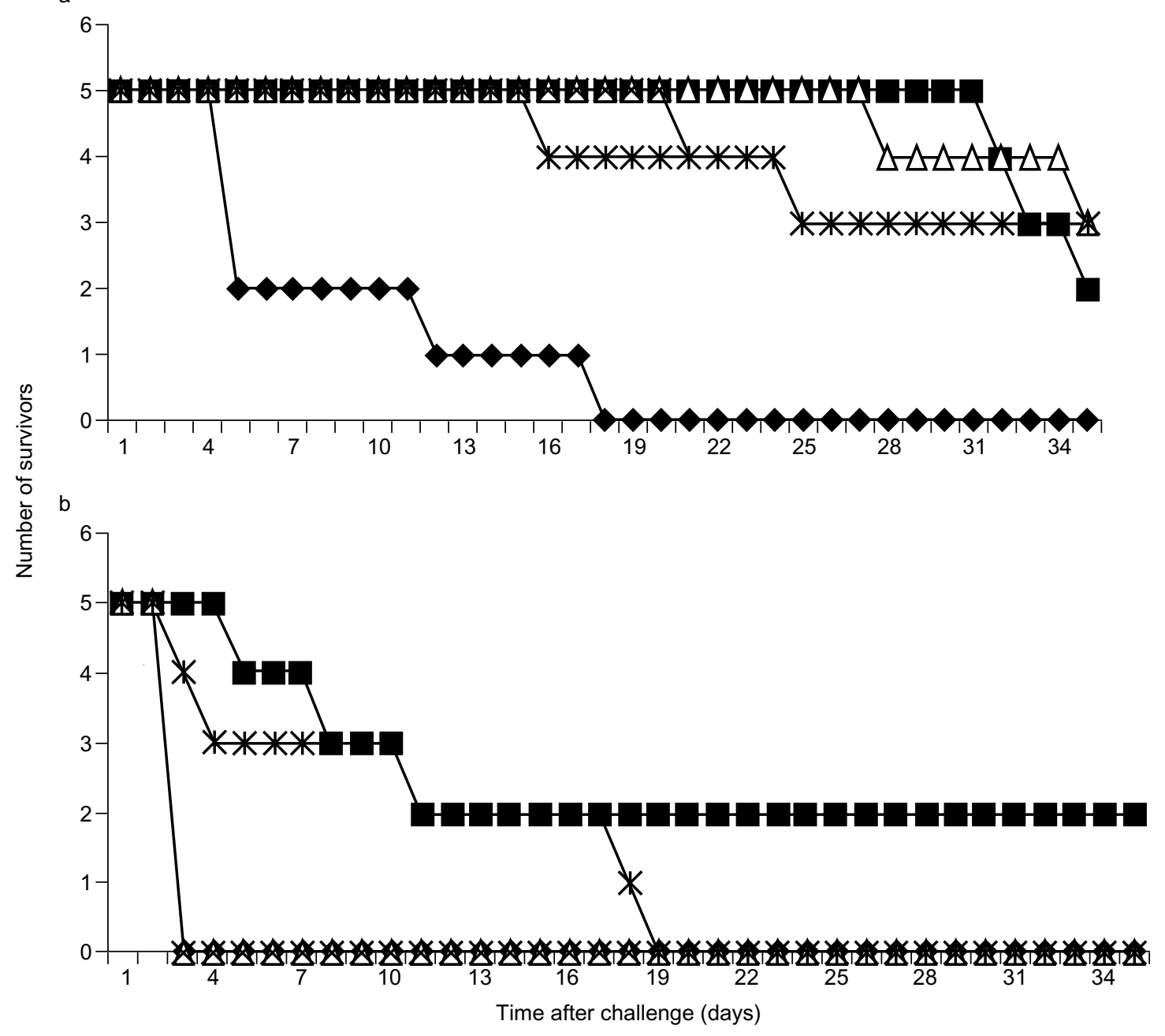

Fig. 4. Survival in passively immunised and naive control mice following intra-peritoneal challenge with (a) $10^{4} \mathrm{cfu}$ or (b) $10^{6} \mathrm{cfu}$ of B. pseudomallei 4845. Groups of mice $(\mathrm{n}=5)$ were given a cocktail of three MAbs recognising exopolysaccharide ( $\mathbf{\square})$, a MAb recognising LPS $(\triangle)$, three MAbs recognising proteins $(\times)$ or a complete cocktail containing all seven of the MAbs $(*)$. The control groups were untreated.

To determine whether each of the individual antibodies in the cocktails was protective, each MAb was administered independently to groups of six mice, which were then challenged with either $10^{4} \mathrm{cfu}$ or $10^{6} \mathrm{cfu}$ (Fig. 5). After inoculation with $10^{4} \mathrm{cfu}$ of $B$. pseudomallei, all the untreated control mice died by day 4 after challenge. However, in all of the treatment groups, there was significant protection compared with the equivalent untreated group ( $\mathrm{p}<0.01)$. After 35 days there were survivors in the groups that had received the anti-exopolysaccharide antibodies 3 VEI5 or 4VA5, the anti-LPS antibody CC6 or the anti-protein antibody 4VH7. At post mortem examination, all survivors had splenomegaly, with a substantial number exhibiting abscesses on the spleen and liver. In groups that had received a challenge of $10^{6} \mathrm{cfu}$, only mice given 4VA5 or 3EVI5 anti-exopolysaccharide MAbs demonstrated a significantly delayed time to death $(p<0.05)$ compared with the untreated control group. Neither the anti-LPS $\mathrm{MAb}$ nor any of the anti-protein MAbs provided significant protection at the $10^{6} \mathrm{cfu}$ challenge compared with the untreated control.

\section{Discussion}

B. pseudomallei NCTC 4845 causes a rapidly invasive and lethal infection in the BALB/c mouse model when given intraperitoneally. This model of infection appears to be similar to the acute, fulminant, systemic infection seen in many human melioidosis patients. However, melioidosis does have other clinical presentations and these include a chronic abscess-producing infection and a quiescent infection that may take several years to become symptomatic [25].

In this study MAbs to a number of B. pseudomallei antigens including the exopolysaccharide, lipopolysaccharide and protein antigens, were produced. As yet, the identities of the protein antigens are unknown and, therefore, it is not possible to speculate on their function. There is a substantial body of data suggesting that capsules are important in the virulence of gramnegative and gram-positive bacteria. In particular, polysaccharide capsules protect bacteria in their interaction with host defence systems, for example, from 


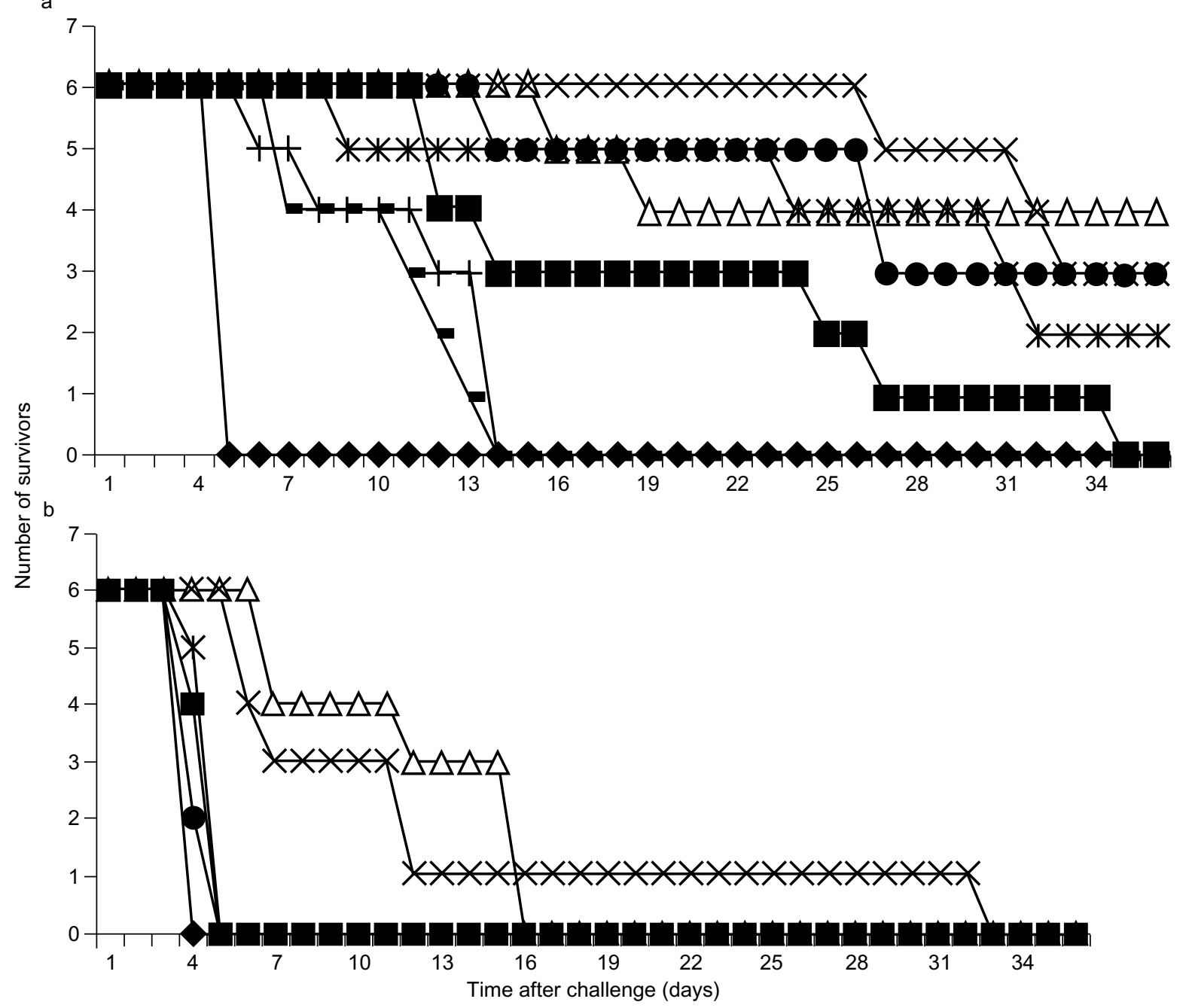

Fig. 5. Survival in passively immunised and untreated control mice following intra-peritoneal challenge with (a) $10^{4} \mathrm{cfu}$ or (b) $10^{6} \mathrm{cfu}$ of $B$. pseudomallei 4845 . Groups of mice $(\mathrm{n}=6)$ were given one of seven MAbs just before challenge: 4IIIAII $(\bullet), 3 \mathrm{VEI} 5$ $(\square), 4$ VA5 $(\Delta)$, CC6 $(*), 4 V H 7(\bullet)$, BA2 $(+)$ or LF7 (-).

complement activation and phagocyte-mediated killing $[26,24]$. More recently, it has been confirmed that the capsular exopolysaccharide of $B$. pseudomallei is an important virulence factor, as insertional inactivation of the biosynthetic pathway resulted in an acapsular mutant with an LD50 in mice of $3.5 \times 10^{5} \mathrm{cfu}$ compared with the wild-type LD50 of $<10$ cfu [18].

MAbs were administered intravenously just before challenge to simulate an infection in individuals with pre-existing high serum titres of specific antibodies, as might be induced by an effective vaccine. The administration of a cocktail of MAbs demonstrated a significant protective effect against a challenge dose of $10^{4}$ or $10^{6} \mathrm{cfu}$ of $B$. pseudomallei. When the protection afforded by the complete cocktail was compared with that given by the antibodies to specific antigens it appeared that all the specific MAbs gave protection equivalent to the complete cocktail at a challenge of $10^{4} \mathrm{cfu}$. However, at a challenge of $10^{6} \mathrm{cfu}$ only the complete antibody cocktail and the anti-exopolysaccharide MAb treatment groups demonstrated a significantly delayed time to death.
When the individual MAbs were tested against a challenge dose of $10^{4} \mathrm{cfu} B$. pseudomallei, the antiprotein MAbs provided significant protection compared with the untreated control group. Despite this they appeared to perform less well than the anti-LPS and anti-exopolysaccharide MAbs. However, the only MAbs to provide any protection against the higher dose of $10^{6} \mathrm{cfu} B$. pseudomallei were the antiexopolysaccharide MAbs 3 VEI5 and 4VA5. The ability of the anti-exopolysaccharide and anti-LPS MAbs to protect against $B$. pseudomallei is in agreement with previous observations regarding these antigens and their role in inducing a protective immune response against melioidosis $[9,11,19]$. It seems likely that antibody bound to surface-expressed capsular polysaccharide and LPS enhance phagocytosis by macrophages and neutrophils and may enhance subsequent killing of internalised bacteria. It is also possible that complement fixation and subsequent bacterial killing is another mode of action of these MAbs. Certainly, anti-polysaccharide antibodies have been shown to enhance opsonophagocytosis of other gram-negative bacteria [27]. Serological studies suggest that anti- 
bodies against LPS II are protective against fatal melioidosis [11] rather than antibodies against LPS I. It is not known which LPS is recognised by MAb CC6 and further work would be required to determine this. However, we have shown that strain 4845 produces a typical B. pseudomallei LPS profile (data not shown), and the MAb reacts with this in Western blots.

It is not clear how the antibodies to the protein antigens function. These proteins may be surface-expressed and, therefore, the MAbs against them may act in the same ways as the antibodies against capsular polysaccharide and LPS. However, it is also possible that these are secreted proteins with an essential function, which the antibodies impair or prevent. Further work to identify these proteins is currently taking place and they may be potential components of a sub-unit vaccine for $B$. pseudomallei.

In the second challenge experiment, it was believed that the breakthrough in protection seen in the treated groups towards the end of the challenge might have been due to degradation of the passively transferred antibodies. However, administration of a second dose of MAbs on day 18 did not significantly increase survival in any treatment group (data not shown). This is a result of some significance because it suggests that the limit of protection was not determined by the amount of antibody alone. This would suggest that antibody is only protective in the initial stages of infection and is then less important or ineffective. The most likely explanation for this would be if the bacteria were living intracellularly and that once within a host cell they are able to spread with little or no extracellular phase. It is known that B. pseudomallei can invade epithelial cells and grow intracellularly within phagocytes $[28,29]$. Thus, the MAbs could act to prevent the colonisation of the intracellular niche, but once the bacteria had established an intracellular infection the presence of high titre, specific antibody may be irrelevant. The immune response induced in mice that survived challenge was not determined and the protection afforded by the MAbs may have been augmented by innate or induced immune mechanisms in the survivors.

A strong cell-mediated cytotoxic response would be required to eliminate infected cells. Previous work has shown that survival in acute infection depends on the production of interferon (IFN)- $\gamma$ by both NK cells and $\mathrm{CD}^{+} \mathrm{T}$ cells. The role of IFN- $\gamma$ in this case would appear to be to induce both NO- and oxygen-dependent killing of bacteria within infected phagocytes [30,31]. Unfortunately, passive administration of MAbs does not stimulate this kind of cell-mediated immune response; this would require active immunisation.

The presence of high titre, highly specific antibodies at least to the capsular polysaccharide and LPS (and possibly other components) contributes to the initial control of infection. However, an optimal vaccine would be required to induce potent specific cellmediated immune responses that would be able to clear infected cells and prevent B. pseudomallei from establishing a chronic infection. How this is to be achieved is currently unknown but the development of a live attenuated mutant of $B$. pseudomallei may induce this type of immune response.

We thank Mrs Debbie Bell for technical support and Professor Rick Titball for guidance and advice throughout this project.

\section{References}

1. Pitt TL. Pseudomonas mallei and P. pseudomallei. In: Parker MT, Duerden BI (eds) Topley and Wilson's Principles of bacteriology, virology and immunity, vol II, 8th edn. Systematic bacteriology. London, Edward Arnold. 1990: 265-273.

2. Dance DAB. Melioidosis: the tip of the iceberg? Clin Microbiol Rev 1991; 4: 52-60.

3. Currie B. Melioidosis in Papua New Guinea: is it less common than in tropical Australia? Trans R Soc Trop Med Hyg 1993; 87: 417.

4. Jenney AWJ, Lum G, Fisher DA, Currie BJ. Antibiotic susceptibility of Burkholderia pseudomallei from tropical northern Australia and implications for therapy of melioidosis. Int J Antimicrob Agents 2001; 17: 109-113.

5. Vedros NA, Chow D, Liong E. Experimental vaccine against Pseudomonas pseudomallei infections in captive cetaceans. Dis Aqu Org 1988; 5: 157-161.

6. Dannenberg AM, Scott EM. Melioidosis: pathogenesis and immunity in mice and hamsters. II. Studies with avirulent strains of Malleomyces pseudomallei. Am J Pathol 1958; 34: 1099-1121.

7. Levine HB, Maurer RL. Immunisation with an induced avirulent auxotrophic mutant of Pseudomonas pseudomallei. J Immunol 1958; 81: 433-438.

8. Brett PJ, Mah DCW, Woods DE. Isolation and characterisation of Pseudomonas pseudomallei flagellin proteins. Infect Immun 1994; 62: 1914-1919.

9. Bryan LE, Wong S, Woods DE, Dance DAB, Chaowagul W. Passive protection of diabetic rats with antisera specific for the polysaccharide portion of the lipopolysaccharide isolated from Pseudomonas pseudomallei. Can J Infect Dis 1994; 5: 170-178.

10. Perry MB, MacLean LL, Schollaardt T, Bryan LE, Ho M. Structural characterization of the lipopolysaccharide $\mathrm{O}$ antigens of Burkholderia pseudomallei. Infect Immun 1995; 63: 3348-3352.

11. Charuchaimontri C, Supputtamongkol Y, Nilakul C et al. Antilipopolysaccharide II: an antibody protective against fatal melioidosis. Clin Infect Dis 1999; 29: 813-818.

12. Kanai K, Kondo E. Recent advances in biomedical sciences of Burkholderia pseudomallei. Jpn J Med Sci Biol 1994; 47: 1-45.

13. Popov S, Kurilov V, Iakovlev A. Pseudomonas pseudomallei and Pseudomonas mallei are capsule forming bacteria. $\mathrm{Zh}$ Mikrobiol Epidemiol Immunobiol 1995; 5: 32-36.

14. Puthucheary S, Vadivelu J, Ce-Cile C, Kum-Thong W, Ismail G. Electron microscopic demonstration of extracellular structure of Burkholderia (Pseudomonas) pseudomallei. Am J Trop Med Hyg 1996; 54: 313-314.

15. Ahmed K, Encisco H, Masaki H et al. Attachment of Burkholderia pseudomallei to pharyngeal epithelial cells: a highly pathogenic bacteria with low attachment ability. Am J Trop Med Hyg 1999; 60: 90-93.

16. Pruksachartvuthi S, Aswapokee N, Thankerngpol K. Survival of Pseudomonas pseudomallei in human phagocytes. $J$ Med Microbiol 1990; 31: 109-114.

17. Brett P, Woods D. Pathogenesis of and immunity to melioidosis. Acta Tropica 2000; 74: 201-210.

18. Reckseidler SL, DeShazer D, Sokol PA, Woods DE. Detection of bacterial virulence genes by subtractive hybridisation: identification of capsular polysaccharide of Burkholderia pseudomallei as a major virulence determinant. Infect Immun 2001; 69: 34-44. 
19. Atkins $\mathrm{T}$, Prior $\mathrm{R}$, Mack $\mathrm{K}$ et al. Characterisation of an acapsular mutant of Burkholderia pseudomallei identified by signature tagged mutagenesis. J Med Microbiol 2002; 51: 539-547.

20. Chart H. Lipopolysaccharide: isolation and characterisation. In: Raton B, Arbor A (eds) Methods in practical laboratory bacteriology. London, CRC Press. 1994: 11-20.

21. Harlow E, Lane D. Antibodies: a laboratory manual. Cold Spring Harbor, NY, Cold Spring Harbor Laboratory Press. 1988

22. Laemmli EK. Cleavage of structural proteins during the assembly of the head of the bacteriophage T4. Nature 1970; 227: $680-685$.

23. Chart H. Sodium dodecyl sulfate-polyacrylamide gel electrophoresis for the separation and resolution of bacterial components. In: Raton B, Arbor A (eds) Methods in practical laboratory bacteriology. London, CRC Press. 1994: 21-33.

24. Steinmetz I, Rohde M, Brenneke B. Purification and characterisation of an exopolysaccharide of Burkholderia (Pseudomonas) pseudomallei. Infect Immun 1995; 63: 3959-3965.

25. Russell P, Eley S, Ellis J et al. Comparison of efficacy of ciprofloxacin and doxycycline against experimental melioidosis and glanders. $J$ Antimicrob Chemother 2000; 45: 813-818.

26. Poxton IR, Arbuthnott JP. Determinants of bacterial virulence. In: Parker MT, Collier LH (eds) Topley and Wilson's Principles of bacteriology, virology and immunity, vol I, 8th edn. London, Edward Arnold. 1990: 332-351.

27. Ho M, Schollaardt T, Smith MD et al. Specificity and functional activity of anti-Burkholderia pseudomallei polysaccharide antibodies. Infect Immun 1997; 65: 3648-3653.

28. Pier GB, Thomas DM. Characterisation of the human immune response to a polysaccharide vaccine from Pseudomonas aeruginosa. J Infect Dis 1983; 148: 206-213.

29. Jones AL, Beveridge TJ, Woods DE. Intracellular survival of Burkholderia pseudomallei. Infect Immun 1996; 64: 782-790.

30. Santanirand P, Harley VS, Dance DAB, Drasar BS, Bancroft GJ. Obligatory role of gamma interferon for host survival in a murine model of infection with Burkholderia pseudomallei. Infect Immun 1999; 67: 3593-3600.

31. Lertmemongkolchai G, Cai G, Hunter CA, Bancroft GJ. Bystander activation of $\mathrm{CD} 8+\mathrm{T}$ cells contribute to the rapid production of IFN-gamma in response to bacterial pathogens. J Immunol 2001; 166: 1097-1105. 